\title{
The Formation of a Self-Funded Global Health Fellowship within a Department of Family Medicine
}

\author{
Christopher Sanford $^{1,}$, Claire Fung ${ }^{1}$, James K. Sherwood ${ }^{1}$, Anna McDonald ${ }^{1}$, Eric Tobiason ${ }^{1}$, Thomas E. Norris ${ }^{1}$ \\ ${ }^{1}$ Department of Family Medicine, University of Washington, Seattle, WA, USA \\ "Corresponding Author: Christopher Sanford, MD, MPH, DTM\&H, Associate Professor, Family Medicine, Global Health, 314 NE Thornton \\ Place, University of Washington, Seattle, WA 98125 USA. Tel: 206-528 8000, Fax: 206-520 2399, Email: casanfo@uw.edu
}

\begin{abstract}
Introduction: The need for global health training for early-career family medicine physicians is greater than the supply. This paper details the formation of a one-year, self-funded global health fellowship for early-career family medicine physicians.

Methods: In August of 2012, the University of Washington Department of Family Medicine established a self-funded, non-ACGME (Accreditation Council for Graduate Medical Education)-accredited fellowship in global health. The fellowship is targeted at early-career family medicine physicians. During the one-year fellowship, the global health fellow rotates through a variety of clinics in the greater Seattle area, including HIV, TB, STD, and other infectious disease clinics. Other activities include selected global health courses at the University of Washington, practice in a continuity clinic seeing both family medicine and pre- and post-travel patients, and a variety of teaching, speaking, and publishing opportunities. The fellow may spent up to two months overseas engaged in clinical practice and/or research; one option for fellows is to work and teach at the district hospital in Naivasha, Kenya, at which the University of Washington has established an ongoing teaching and practice program.

The majority of the fellow's salary and benefits is funded by the fellow's clinical activities. This funding mechanism allowed the fellowship to be launched with minimal of institutional financial support.

Results: Of the first three graduating fellows, two now practice primarily in the US and one works in Malawi with Seed Global Health. The fifth fellow will begin in August 2016. The robust and increasing number of applications suggest that this fellowship is meeting an ongoing need.

Conclusion: This fellowship demonstrates that the need for global health training of early-career, family medicine physicians can at least be met in part by self-funded fellowships of this nature.
\end{abstract}

Keywords: Global Health, Fellowship, Family Medicine, Travel Medicine, Tropical Medicine, Post-Graduate Education

Article History: Received: 4 Apr. 2016; Accepted: 7 May. 2016; Online Published: 25 Jun. 2016

Cite this article as: Sanford C, Fung C, Sherwood JK, McDonald A, Tobiason E, Norris TE. The formation of a self-funded global health fellowship within a department of family medicine. Int J Travel Med Glob Health. 2016;4(2):47-52. doi: 10.20286/ijtmgh-04023

\section{Introduction}

The goal of the University of Washington Department of Family Medicine Global Health Fellowship, founded in the summer of 2012, is to train early-career family medicine physicians in global health clinical skills, education, leadership, policy, and research. This one-year fellowship is comprised of clinical rotations in specialty infectious disease clinics, courses in global health at the University of Washington, a primary care/family medicine continuity clinic, scholarly work, and the option of an overseas rotation of up to two months. Currently the program is limited to board-certified or board-eligible family medicine physicians. This program is currently non-ACGME (Accreditation Council for Graduate Medical Education) accredited and is largely self-funded by income generated from the clinical activities of the participating fellow.

Massive global health disparities persist, with residents of the poorest nations having an average life expectancy of less than 50 years $[1,2]$. Medical trainee interest in global health training has been increasing at an unprecedented rate; current availability of global health training is insufficient to meet the demand [3].

A 2013 study of 521 physicians with formal training in clinical and health services, research, and policy leadership found that $85 \%$ felt their global health activities had enhanced the quality of their domestic work and increased their level of involvement with vulnerable populations, health policy advocacy, or research on the social determinants of health. However, a significant number of respondents in that study noted a lack of specific avenues for career development in global health [4].
The University of Washington has recently developed a strong Department of Global Health. Several Family Medicine faculty members have joint or adjunct appointments in Global Health, and there is an intense and growing interest in public health among medical students and residents at the University of Washington. With the goal of expanding training in global health, the University of Washington Department of Family Medicine Global Health Fellowship was founded in 2012.

Although medical trainee interest in global health has been growing over the last several years, there remain few opportunities at the fellowship level across all specialties. A study survey in 2011 identified 14 family medicine fellowship programs across the United States; however, for each of the programs identified, "fellowship" was inclusive of training that was integrated into residency. None of the 14 family medicine programs listed included post-residency fellowship training [3]. The American Association of Family Physicians (AAFP) hosts an online directory of fellowship opportunities. As of April 2015, the University of Washington Family Medicine Global Health Fellowship was one of only three listings under the fellowship type "F[5].

Table 1 lists six family medicine global health fellowships found by the Internet search engine Google with the search term: "Family Medicine Global Health Fellowship."

Pfeiffer et al. [6] conducted in-depth interviews with leaders in global health on the topic of anticipated key roles and competencies for global health professionals in the future. Interviewees identified the determinants of health and systems thinking as two high-priority areas of knowledge; they also identified analytical, leadership and management, 
and policy-development skills as important skill sets. Interviewees also felt that training in global health should focus on experiential learning, interdisciplinary and inter professional collaboration, and information analysis and synthesis.

Table 1. Fellowships in Family Medicine

\begin{tabular}{lcc}
\hline Fellowship Name & Year Started & Website \\
\hline Via Christi International Family Medicine Fellowship & 2010 & http://www.vcfm.net/fellowships/international-medicine-fellowship/ \\
$\begin{array}{l}\text { Contra Costa Regional Medical Center (CCRMC)/Massachusetts } \\
\text { General Hospital (MGH) Fellowship In Global Health Leadership }\end{array}$ & 2011 & http://cchealth.org/residency/mgh-fellowship/ \\
$\begin{array}{l}\text { Family Medicine Global Health Faculty Development Fellowship } \\
\text { at Alpert Medical School of Brown University }\end{array}$ & 2011 & http://www.brownfamilymedicine.org/education/GlobalHealth/Globa \\
$\begin{array}{l}\text { University of Washington Family Medicine Global Health } \\
\text { Fellowship }\end{array}$ & 2012 & http://depts.washington.edu/fammed/residency/fellowships/global- \\
health
\end{tabular}

Core skills for each fellow include 1) WHO (World Health Organization) and UNICEF (United Nations Children's Fund) protocols for clinical care in low-resource settings, including IMCI (Integrated Management of Childhood Illness); 2) evidence-based clinical guidelines for immigrants and refugees; 3 ) travel medicine: both pre-travel and post-travel; 4) global health leadership and policy; 5) teaching and mentoring: both medical students and residents in the US and medical professionals in low-resource settings; and 6) research methodology in low-resource settings [7].

\section{Methods}

During the one-year fellowship, each fellow rotates through a variety of specialty clinics in Seattle and King County, including the Tuberculosis Clinic at Public Health-Seattle-King County, the Madison (HIV) Clinic, the Infectious Disease Clinic at Harborview Medical Center, the Travel Clinic at Hall Health Center on the University of Washington campus, and the Hansen's Disease Clinic at Harborview Medical Center. They also have the option of joining Public Health-Seattle \& King County's weekly physicians' meetings and didactics. In addition to the clinics mentioned above, the 2014-15 fellow rotated through the King County STD clinic located at Harborview Medical Center, Seattle, spent three months rotating at Harborview's Madison Clinic for a more longitudinal exposure to HIV care, and worked with Planned Parenthood to gain extra skills in family planning, early trimester ultrasound, and manual vacuum aspiration (MVA). An option for future fellows will be to rotate on the HIV in-patient service at Harborview Medical Center. A sample curriculum is presented in Table 2.

As a full-time University of Washington employee, the fellow is exempt from tuition for up to six units per quarter and may enroll in courses from the University of Washington Department of Global Health, School of Public Health, School of Medicine, and other schools and departments. Courses completed by previous fellows include Global Health Leadership and Clinical Management of HIV, both taught through the University of Washington Department of Global Health. Another recommended course for fellows is Essentials of Clinical Care and Capacity Building in LowIncome Countries, also taught through the UW Department of Global Health [8].

Table 2. Sample Curriculum - GH Fellowship

Twelve 1-month blocks

\begin{tabular}{|c|c|c|}
\hline Block 1 & Block 3 & Block 4 \\
\hline TB clinic & Women's Health/Gyn/colposcopy clinic & Course: Global Health Leadership \\
\hline \multicolumn{3}{|c|}{ Longitudinal: Family medicine continuity clinic ( 3 half-days/week) } \\
\hline \multicolumn{3}{|c|}{ Longitudinal: Travel medicine clinic (interspersed in FM clinic) } \\
\hline \multicolumn{3}{|c|}{ Longitudinal: FM clinic preceptor (1 half-day/week) } \\
\hline \multicolumn{3}{|c|}{ Block 7} \\
\hline Infectious Disease clinic & Hansen's Disease clinic & Course: Clinical Management of HIV \\
\hline \multicolumn{3}{|c|}{ Longitudinal: Family medicine continuity clinic } \\
\hline \multicolumn{3}{|c|}{ Longitudinal: FM clinic preceptor } \\
\hline Block 9 & Block 11 & Block 12 \\
\hline FM Ward Attending Research & Overseas/Clinical Research & Research \\
\hline \multicolumn{3}{|c|}{ Longitudinal: Family medicine continuity clinic } \\
\hline \multicolumn{3}{|c|}{ Longitudinal: Travel medicine clinic } \\
\hline \multicolumn{3}{|c|}{ Longitudinal: FM clinic preceptor } \\
\hline
\end{tabular}

The fellow sees both general family medicine and travel medicine patients at the University of Washington Neighborhood Northgate Clinic, a community-based family medicine clinic located in North Seattle, for an average of four half-days per week. Many of the continuity patients are foreign-born and require interpreters. Pre-travel patients include a significant number who fall into special groups, including those returning to low-resource settings to visit friends and family (VFRs), immunocompromised travelers, and pediatric travelers. Also, the fellow serves as a resource for residents on topics pertaining to pre- and post-travel medicine and infectious diseases endemic to low-resource settings.

The fellow has a variety of opportunities for leadership development through teaching and speaking. Fellows serve as preceptors in the University of Washington Family Medicine Residency Clinic one half-day per week, during which they supervise residents who see a full-spectrum of 
family medicine patients. This allows them to practice clinical teaching skills, which are essential for capacitybuilding abroad. The fellow coordinates with the family medicine chief resident regarding presenting lectures to family medicine residents on a variety of topics pertinent to global health. Each fellow presents two workshops on PreTravel Case Studies at the annual Advances in Family Practice and Primary Care, University of Washington, Seattle, co-presenting with Dr. Christopher Sanford. Fellows also give presentations to University of Washington firstyear medical students, a local high school, and the University of Washington Department of Family Medicine Global Health Interest Group. The 2014-2015 fellow also gave a series of presentations on global health to other University of Washington network residency programs. Additionally, each fellow sits on the planning committee for the Update: Global Health \& Travel Medicine, a two-and-a-half day biennial conference hosted by the University of Washington in Seattle.

A goal of the fellowship is for each fellow to publish at least one paper during or within one year of finishing the fellowship. Fellows' publications to date include a chapter in the $5^{\text {th }}$ edition of The Travel and Tropical Medicine Manual, edited by Christopher Sanford, Paul Pottinger, and Elaine Jong (Elsevier, 2016), and a chapter in Medical Clinics of North America, on Travel and Adventure Medicine, edited by Paul Pottinger and Christopher Sanford (Elsevier, 2016). Additionally, two papers, one on the pre-travel encounter and another on the pediatric pre-travel encounter, are now being submitted for publication.

Two faculty members who work within the University of Washington's Department of Family Medicine Research Division serve as consultants on fellows' research projects regarding research methodology and biostatistics. Additionally, fellows are encouraged to present their projects at the UW Department of Family Medicine's monthly Works in Progress meetings, at which junior faculty critique one another's research projects. The University of Washington Department of Family Medicine also hosts an annual Department Fair that provides an opportunity for fellows to submit projects for either oral or poster presentation.

Although the World Health Organization (WHO) has published a list of effective and ineffective behaviors as its Global Competency Model [9], there are no agreed-upon competencies for training within global health; each training program tends to define its own [10]. A 2010 review article that looked at 32 papers on global health competencies in medical school found that, "The most frequently mentioned competencies included an understanding of the global burden of disease, travel medicine, healthcare disparities between countries, immigrant health, primary care within diverse cultural settings, and skills to better interface with different populations. However, no consensus on global health competencies for medical students was apparent" [11]. One model of global health competencies, the Global Health Competency Model 1.1, which includes seven domains and 36 competencies, developed by the Association of Schools of Public Health (ASPH) for master-level public health students, may serve as a framework for the nonclinical aspects of competencies [12]. Currently, under the leadership of Dr. Fadya el Rayess at Brown University (Rhode Island, US) and others, several of the US global health fellowships are discussing a process by which common competencies can be delineated.
A 1963 CMAJ (Canadian Medical Association Journal) editorial stated, "If, as a routine, young American doctors were encouraged to spend some months working in a developing country before they became tied to the responsibility of practice, the result could only be better medicine at home and abroad [13]." Residents have listed financial difficulties, scheduling conflicts, and lack of available time as barriers to international rotations [14, 15]. By blocking out two months of dedicated time for work overseas and providing a salary at the R4 Resident/Fellow level, this fellowship helps to mitigate these barriers.

Work in low-resource settings has been shown to have favorable effects on trainees' knowledge, attitudes, and skills $[16,17]$. It has been demonstrated that health science students who engage in global health field experiences are more likely to enter into primary care medicine; report improved diagnostic skills and heightened interest in volunteerism, humanitarianism, and public health; and, postresidency, to care for low-income and ethnic minority patients [18, 19]. Although rotations during medical school may provide an introduction to international health, physicians will have a better clinical context if they work overseas during residency or a fellowship [20].

It must be acknowledged, however, that medical providers from high-income nations who volunteer in low-income nations have the capacity to cause significant harm [21]. Being cognizant of and endeavoring to follow best practice guidelines will maximize the likelihood that overseas volunteers will act in an ethical manner and offer significant benefits to the populations with whom they work [22].

The fellow may spend up to two months at an international site at which s/he can engage in clinical activities and/or perform research. The 2012-13 fellow spent two months in Burundi providing clinical care and performing research on a project related to screening for cervical cancer in lowresource settings at the Sharon McKenna Health Center of Village Health Works in Kigutu. The 2014-2015 fellow used this time to complete the Gorgas Course in Clinical Tropical Medicine, an intensive nine-week course administered by the University of Alabama and the Universidad Peruaña Cayetano Heredia (UPCH) in Lima, Peru. The course focuses on didactic teaching sessions from some of the world's experts in tropical and neglected diseases, combined with clinical bedside rounds and laboratory sessions that focus on interpreting diagnostic tests commonly used in the developing world. Completion of this course allows fellows to graduate with a Diploma in Tropical Medicine and Hygiene (DTM\&H) and to sit for the Certificate of Knowledge in Clinical Tropical Knowledge and Traveler's Health (CTropMed®), an annual exam given by the American Society of Tropical Medicine and Hygiene (ASTMH).

The Global Health Fellowship is a non-ACGME-approved position, so funding must come from internal resources. These sources include both the fellow's clinical care and support from the Department of Family Medicine. The University of Washington Department of Family Medicine partners with the University of Washington Medicine Healthcare System to identify a clinical training site of practice for the fellow to work to offset the expense of their salary and benefits.

The fellow is scheduled at the University of Washington Medicine Neighborhood Northgate Clinic in Seattle, Washington (approximately four miles north of the main 
University of Washington campus and Medical Center). Factoring in a two-month overseas global health rotation, vacation, scholarship, and research activities, the fellow must see patients at four half-day clinics per week $(0.40$ FTE) over a 10-month period to provide the clinical income needed to cover the annual salary and benefits of the fellow. The fellow's annual salary stipend is set at the ACGME approved R4 Resident/Fellow level salary plus two percent. The 2015-16 base salary is $\$ 60,108$.

The non-salary expenses associated with the fellow are funded out of indirect costs received by the department for the fellow's clinical billing as well as from other departmental resources. $\$ 2,000$ per year is allocated to support continuing professional development and CMErelated travel expenses for the fellow to attend professional meetings. The fellow is responsible for covering the cost of travel, tuition for University of Washington courses, dues for professional societies, and other professional costs associated with training in the fellowship that are not covered as part of the baseline $\$ 4,000$ funding.

The Fellowship Director, Christopher Sanford, MD, receives two hours per week of paid administrative time from the UW Department of Family Medicine to oversee the fellowship.

By the end of the fellowship, fellows will be qualified to sit for the Certificate in Travel Health exam, which is offered annually by the International Society of Travel Medicine (ISTM). Those completing a Diploma in Tropical Medicine and Hygiene (DTM\&H) program will be eligible to sit for the Certificate of Knowledge in Clinical Tropical Medicine \& Traveler's Health, which is administered annually by the ASTMH (American Society of Tropical Medicine \& Hygiene).

Evaluation is tri-directional, involving evaluation of the fellow, evaluation of the program, and the fellow's evaluation of the program and faculty. Following each clinical rotation, an evaluation form is sent to the rotation director which asks about the fellow's attendance and performance. The fellowship director meets with the fellow regularly to discuss those evaluations. The fellow evaluates each clinical rotation and fellowship faculty member. The fellowship faculty meets once per year and reviews both the fellow's progress to date and the extent to which the fellowship is meetings its goals.

The Global Health Fellowship Internal Advisory Board and External Advisory Board are comprised of faculty members within the University of Washington's Departments of Family Medicine and Global Health. The duties of these boards include advising the fellowship director regarding administration of the fellowship, critiquing educational priorities, and recommending strategies for program growth and improvement. As a general rule, the Internal Advisory Board advises concerning training (e.g., clinical rotations and coursework); the External Advisory Board advises concerning fellowship priorities, goals, and funding.

To date, publicity for the fellowship has been informal. Initially, information about the fellowship was spread primarily by word-of-mouth. Individuals involved in the fellowship contacted potentially interested parties through their professional networks (alumni groups, etc.). Additionally, this program was included on a list of postresidency training programs on the websites of the AAFP and the WWAMI residency network. A website (http://depts.washington.edu/fammed/residency/fellowships /global-health) serves as a resource for those interested in the fellowship. Awareness of the fellowship was also raised through a formal presentation at a Society of Teachers of Family Medicine (STFM) conference and with brochures at an AAFP National Conference for Residents and Medical Students. Informal assessment showed that those who inquired about or applied for the 2013-2014 academic year had heard about the program through word-of-mouth, the AAFP list of post-residency training programs, or the fellowship website.

We expect that awareness of our training program will be increased in the future through more conference presentations and publications. We also hope to work with professional societies including the Society of Teachers of Family Medicine (STFM), American Academy of Family Practitioners (AAFP), International Society of Travel Medicine (ISTM), and American Society of Tropical Medicine and Hygiene (ASTMH), to increase awareness of the fellowship through their listservs, newsletters, conferences, and other publications. Given the potential overlapping interests, we also hope to share our fellowship with EIS officers with the CDC at their annual conference. Furthermore, we hope networks of residency program directors and coordinators can share information about the fellowship with their senior residents.

Applications are due December 15 for the cycle that begins the following July 1; required materials include a cover letter, three letters of recommendation (including one from residency program director), a $\mathrm{CV}$, a personal statement, a copy of USMLE/COMLEX transcript, a copy of medical school diploma and transcript, a certificate or other validation of all previous training, and a copy of current state medical licensure. Optional supporting items that may be considered, but are not mandatory, include a medical school dean's letter, additional letters of recommendation, and the resident's rotation schedule.

Selected applicants are invited to interview in Seattle February 15-28; applicants are notified regarding acceptance in mid-March. Consideration is currently being given to moving these dates earlier, such that they are identical to those for ACGME-accredited fellowships (application deadline of September 30).

\section{Results}

The fourth fellow will complete her fellowship in the summer of 2016. Of the first three graduating fellows, two practice primarily in the United States, and one works in Malawi with Seed Global Health which partners with the Peace Corps and the US President's Emergency Plan for AIDS Relief (PEPFAR).

The fellows to date have felt that their year of fellowship was well spent. The 2013-14 fellow stated, "The time I spent as a Global Health Fellow was invaluable. I was able to craft my fellowship to suit my particular interests and needs for my career straddling between local and international medical pursuits. I particularly valued the access to knowledgeable faculty and clinicians in many disciplines, the opportunity to develop teaching skills in teaching/supervising medical students and residents, and the strong mentoring in travel medicine."

The 2014-15 fellow stated, "I completed my fellowship in the 2014-2015 academic year and it was the perfect opportunity for me to expand my infectious disease and 
tropical medicine knowledge while continuing to practice full spectrum family medicine. In addition to doing rotations at the Harborview STD Clinic, Leprosy Clinic, Madison (HIV) Clinic, and TB clinics, I was also able to complete the Gorgas course in Peru, which allowed me to graduate with a diploma in Tropical Medicine \& Hygiene. I will be leaving the fellowship to start a position with the Global Health Service Corps (run by the Peace Corps and SEED global health) in Malawi, where I will be working on an academic development project in collaboration with the College of Medicine in Malawi. I am so thankful for all of the teaching and exposure to international experts in the field that this fellowship has given me."

The fifth Fellow will begin in August 2016.

\section{Discussion}

In three to five years, this program could be transitioned to one which is ACGME-accredited. This accreditation would have the advantage of allowing fellows to perform less general family medicine clinic and devote a higher proportion of their time to specific global health pursuits. The process of transitioning to an ACGME-accredited program involves completing an application document, paying a non-refundable fee, and, potentially, a site visit [23]. This process requires as long as seven to ten months for programs requiring a site visit. Currently, ACGME does not accredit fellowships in global health. Significant national work would be required for ACGME to accredit this type of fellowship.

Global health is intrinsically interdisciplinary and multidisciplinary [24]. This program could benefit from linking to other primary care global health fellowships, including those within internal medicine and pediatrics. Consideration could be given to expanding this program such that it accepts more than one fellow each year. Additionally, it could accept early career physicians in primary care specialties other than family medicine.

Potentially, future fellows would have the option of combining this program with a Masters in Public Health from the University of Washington during a two-year course of study. Similarly, fellows could enroll in a DTM\&H (Diploma, Tropical Medicine \& Hygiene) program in conjunction with the one-year fellowship. For fellows with an interest in clinical work in Africa, one option is the East African Diploma Course in Clinical Tropical Medicine (12 weeks, offered in Tanzania and Uganda), for which the University of Washington is one of five academic institutional partners [25].

As the fellowship matures, additional dedicated monies for staff support, publicity, and other expenses will be necessary. Further expansion of the current support for continuing medical education (CME), dues for professional societies, and travel would also strengthen the fellowship.

\section{Conclusion}

Currently the demand for post-graduate training in global health among primary care physicians exceeds its supply. Established in 2012, the University of Washington Department of Family Medicine Global Health Fellowship provides future clinicians, researchers, teachers, and leaders within the field of global health focused and intensive oneyear training in key areas within their field. The self-funding model allowed the fellowship to be established with minimal extrinsic funding. In future years the fellowship may transition to one which is ACGME-accredited; it may expand to accept more than one fellow per year; it may broaden its applicant base by allowing specialties other than family medicine to apply.

\section{Acknowledgments}

The fellowship is indebted to members of the Internal and External Advisory Boards, particularly to their respective chairs, Drs. Jaqueline Raetz (UW Department of Family Medicine) and Joseph Zunt (UW Department of Global Health), for their oversight, and to the fellowship faculty for sharing their expertise. The fellowship is also indebted to Drs. Tom Norris and Kim Harmon, both of whom shared valuable advice during the planning of this program. Thanks to Dr. Bill Phillips for information regarding traditional roles of internal and external review boards, and to Dr. Claire Fung for creating the fellowship web site and a variety of other tasks related to establishing and operating the fellowship.

\section{Authors' Contributions}

All authors contributed significantly towards the study.

\section{Financial Disclosure}

None.

\section{Funding/Support}

None.

\section{References}

1. CIA World Fact book, 2012 [June 14, 2013]. Available from: https://www.cia.gov/library/publications/the-worldfactbook/rankorder/2102rank.html.

2. The World Bank, 2013 [June 14, 2013]. Available from: http://data.worldbank.org/indicator/SP.DYN.LE00.IN

3. Nelson B, Izadnegahdar R, Hall L, Lee PT. Global Health fellowships: a national, cross-disciplinary survey of US training opportunities. J Grad Med Educ. 2012;4(2):184-9. doi: 10.4300/JGME-D-11-00214.1

4. Greysen SR, Richards AK, Coupet S, Desai MM, Padela AI. Global health experiences of US physicians: a mixed methods survey of clinician-researchers and health policy leaders. Global Health. 2013;9:19. doi: 10.1186/1744-8603-9-19

5. American Academy of Family Practice, 2015 [April 19, 2015]. Available from: http://www.aafp.org/home.html.

6. Pfeiffer J, Beschta J, Hohl S, Gloyd S, Hagopian A, Wasserheit J. Competency-based curricula to transform global health: redesign with the end in mind. Acad Med. 2013;88(1):131-6. doi: 10.1097/ACM.0b013e318276bdf4

7. Pottie K, Greenaway C, Feightner J, Welch V, Swinkels H, Rashid $\mathrm{M}$, et al. Evidence-based clinical guidelines for immigrants and refugees. CMAJ. 2011;183(12):E824-E925. doi: 10.1503/cmaj.090313

8. A complete listing of courses available through the University of Washington's Department of Global Health, 2016 [25 May, 2016]. Available http://globalhealth.washington.edu/academics/courses

9. WHO Global Competency Model, 2015 [April 19, 2015]. Available from:

http://www.who.int/employment/WHO_competencies_EN.pdf.

10. Eichbaum Q. The problem with competencies in global health education. Acad Med. 2015;90(4):414-7. doi: 10.1097/ACM.0000000000000665

11. Battat R, Seidman G, Chadi N, Chanda MY, Nehme J, Hulme J, et al. Global health competencies and approaches in medical education: a literature review. BMC Med Educ. 2010;10:94. doi: 10.1186/14726920-10-94

12. Ablah E, Biberman DA, Weist EM, Buekens P, Bentley ME, Burke D, et al. Improving global health education: development of a Global Health Competency Model. Am J Trop Med Hyg. 2014;90(3):560-5. doi: 10.4269/ajtmh.13-0537

13. Anderson L. International medical aid. CMAJ. 1963;89(5):225. 
14. Powell AC, Mueller C, Kingham P, Berman R, Pachter HL, Hopkins MA. International experience, electives, and volunteerism in surgical training: a survey of resident interest. J Am Coll Surg. 2007;205(1):162-8. doi: 10.1016/j.jamcollsurg.2007.02.049

15. Gupta AR, Wells CK, Horwitz RI, Bia FJ, Barry M. The International Health Program: the fifteen-year experience with Yale University's Internal Medicine Residency Program. Am J Trop Med Hyg. 1999;61(6):1019-23.

16. Haq C, Rothenberg D, Gjerde C, Bobula J, Wilson C, Bickley L, et al. New world views: preparing physicians in training for global health work. Fam Med. 2000;32(8):566-72.

17. Henry JA, Groen RS, Price RR, Nwomeh BC, Kingham TP, Hardy $\mathrm{MA}$, et al. The benefits of international rotations to resource-limited settings for US surgery residents. Surgery. 2013;153(4):445-54. doi: 10.1016/j.surg.2012.10.018

18. Thompson MJ, Huntington MK, Hunt DD, Pinsky LE, Brodie JJ. Educational effects of international health electives on US and Canadian medical students and residents: a literature review. Acad Med. 2003;78(3):342-7. doi: 10.1097/00001888-200303000-00023

19. Gjerde CL, Rothenberg D. Career influence of an international health experience during medical school. Fam Med. 2004;36(6):412-6.
20. Drain PK, Holmes KK, Skeff KM, Hall TL, Gardner P. Global health training and international clinical rotations during residency: current status, needs, and opportunities. Acad Med. 2009;84(3):320. doi: 10.1097/ACM.0b013e3181970a37

21. Crump JA, Sugarman J. Ethical considerations for short-term experiences by trainees in global health. JAMA. 2008;300(12):14568. doi: 10.1001/jama.300.12.1456

22. Crump JA, Sugarman J; Working Group on Ethics Guidelines for Global Health Training (WEIGHT). Ethics and best practice guidelines for training experiences in global health. Am J Trop Med Hyg. 2010;83(6):1178-82. doi: 10.4269/ajtmh.2010.10-0527

23. Leach DC. Accreditation council for graduate medical education. Continuing Education in the Health Professions: Improving Healthcare Through Lifelong Learning. 2007:210.

24. Koplan JP, Bond TC, Merson MH, Reddy KS, Rodriguez MH, Sewankambo NK, et al. Towards a common definition of global health. Lancet. 2009;373(9679):1993-5. doi: 10.1016/S01406736(09)60332-9

25. East African Diploma in Tropical Medicine and Hygiene [April 19, 2015]. Available

from: 